\title{
Evaluation of Long-Term Degree-Days Estimated with Several Methods for Corn in Nebraska, USA
}

Shuwei Dai ( $\nabla$ daishuwei7@gmail.com )

University of Nebraska-Lincoln School of Natural Resources https://orcid.org/0000-0002-4654-2521

Martha D. Shulski

University of Nebraska-Lincoln

Haishun Yang

University of Nebraska-Lincoln

Roger W. Elmore

University of Nebraska-Lincoln

\section{Research Article}

Keywords: degree-days, estimation methods, corn growing season, Nebraska

Posted Date: August 24th, 2021

DOI: https://doi.org/10.21203/rs.3.rs-284619/v1

License: (c) (1) This work is licensed under a Creative Commons Attribution 4.0 International License.

Read Full License 


\section{Abstract}

The concept of thermal time, measured in degree-days, is widely used among the agricultural community in Nebraska to make decisions in corn (Zea Mays L.) production. Instead of the real-time temperatures that are experienced by corn plants, most of the widely available temperature data are limited to daily timescale observations from standard meteorological stations. And a variety of equations are used by different agricultural groups (e.g., researchers, advisors, farmers, and seed companies) to estimate thermal time for corn. Two problems could arise: a) the estimation method is lacking in accuracy; and b) different estimation methods are used for the same purpose by different groups. Consequently, citing these inaccurate and maybe inherently different thermal time results could lead to biased decisions in corn production. The goal of this study is to evaluate six commonly used estimation methods by comparing the estimated thermal time with the hourly-temperature approximated thermal time. We analyzed the root mean square error and mean absolute error for six metrics of total growing season (from May through September) degree-days based on the temperature data from a total of 14 long-term observing locations in Nebraska. In particular, we selected four location-extreme year cases to demonstrate the six methods' estimation performance on a daily timescale. We found that the most commonly used adjusted $T_{\max }$ and $T_{\min }$ rectangle method provided poor estimation in the study area. Instead, single-sine, double-sine, or $T_{\text {avg }}$-based method was more superior depending on the metric of degree-days.

\section{Introduction}

The concept of thermal time (or heat units), measured in degree-days, is widely used in crop research and field management to track crop phenological development (Cross and Zuber, 1972; Gilmore and Rogers, 1958; Russelle et al., 1984). Thermal time is the cumulative measure for temperature-based crop development, and ideally would be measured with temperatures that are actually experienced by the plants. However, most of the widely available temperature data are restricted to observations from meteorological stations that are in the vicinity of crop fields, usually including daily maximum and minimum temperatures. Thermal time is commonly estimated based on these two daily temperatures, with three types of methods as follows: (1) averaging (or so called rectangle) methods, such as $T_{\text {avg }^{-}}$ based method ( $T_{\text {avg }}$ is the arithmetic mean of daily maximum and minimum temperatures) and adjusted $T_{\max }$ and $T_{\min }$ method (Arnold, 1960; McMaster and Wilhelm, 1997); (2) sine-wave methods, such as single-sine method (Baskerville and Emin, 1969), and double-sine method (Allen, 1976); and (3) triangulation methods, such as single-triangulation method (Lindsey and Newman, 1956; Neild, 1967), and double-triangulation method (Sevacherian et al., 1977). Averaging methods are relatively simple to use, especially the $T_{\text {avg }}$-based method, however, using such methods raises a concern that the arithmetic mean of daily maximum and minimum temperatures may not accurately represent the true daily average temperature, as illustrated by Bigelow (1909). The principal assumption of sine-wave and triangulation methods is that the diurnal temperature curve is similar to the trigonometric sine curve or triangulation curve. Double-sine and double-triangulation methods account for the fact that minimum temperature at 
the beginning and the end of a specific 24-hour period may not necessarily be the same; hence, they use the next day's minimum temperature. Specifically, double-sine and double-triangulation methods divide each day into two 12-hour periods and then represent the first 12-hour period by daily minimum and maximum temperatures of that day while representing the second 12-hour period by daily maximum temperature of that day and daily minimum temperature of the following day (Allen, 1976; Sevacherian, et al., 1977).

According to Kumudini et al. (2014), the above-mentioned estimation methods for thermal time are all categorized as empirical linear, based on their temperature response and derivation. Two temperature thresholds are usually involved in an empirical linear estimation method, including a lower threshold below which crop development ceases and an upper threshold above which crop development rate will not further increase. Upper-threshold cut-off techniques include horizontal, vertical, and intermediate (Roltsch et al., 1999). When daily average temperature, the arithmetic mean of daily maximum and minimum temperatures, is used to estimate thermal time, there are three possible situations that need to be considered: (1) daily average temperature is at or above the upper threshold; (2) daily average temperature is at or above the lower threshold but remains below the upper threshold; and (3) daily average temperature is below the lower threshold. When daily maximum and minimum temperatures are directly used to estimate thermal time, there are six possible situations that need to be considered: (1) daily minimum temperature is below the lower threshold, and daily maximum temperature is either: (a) below the lower threshold, (b) at or above the lower threshold but below the upper threshold, or (c) at or above the upper threshold; (2) daily minimum temperature is at or above the lower threshold but below the upper threshold, and daily maximum temperature is either: (a) at or above the lower threshold but below the upper threshold, (b) at or above the upper threshold; or (c) both daily minimum temperature and daily maximum temperature are at or above the upper threshold.

When observed hourly temperature data are available, there would be no need to depict the diurnal temperature curve with daily maximum and minimum temperatures. Instead, thermal time could be more realistically approximated as the number of degree days that hourly temperatures fall between the lower and upper thresholds (Zalom et al., 1983). Zalom et al. (1983) used a 14-day-period dataset to compare thermal time (with a lower threshold of $12.8^{\circ} \mathrm{C}$ and an upper threshold of $32.2^{\circ} \mathrm{C}$ ) derived from five different estimation methods with that based on hourly temperature. McMaster and Wilhelm (1997) compared thermal time for corn estimated with the two types of averaging methods, with a lower threshold of $10^{\circ} \mathrm{C}$ and an upper threshold of $30^{\circ} \mathrm{C}$. Roltsch et al. (1999) evaluated seven different estimation methods for thermal time at nine locations in California during a two-year study period.

In Nebraska, agricultural community for corn widely uses degree-days to choose corn variety, predict corn phenology, and so on. However, different groups (e.g., researchers, agricultural advisors, farmers, seed companies, etc.) have used divergent methods or thresholds to estimate thermal time for corn. In particular, researchers use $T_{\text {avg }}$-based averaging method with a lower threshold of $10^{\circ} \mathrm{C}$ and an upper threshold of $30^{\circ} \mathrm{C}$ (Feng and $\mathrm{Hu}, 2004$ ); agricultural advisors use adjusted $T_{\max }$ and $T_{\min }$ method with a lower threshold of $10^{\circ} \mathrm{C}$ and an upper threshold of $30^{\circ} \mathrm{C}$ 
(https://drinet.hubzero.org/groups/u2u/tools/gdd); seed company Monsanto uses $T_{\text {avg }}$-based averaging method with a lower threshold of $10^{\circ} \mathrm{C}$ but no upper threshold, although this is not well documented; crop simulation model CERES-Maize (Jones and Kiniry, 1986) uses a combination of averaging method and 3hour correction method with a lower threshold of $8^{\circ} \mathrm{C}$ and an upper threshold of $34^{\circ} \mathrm{C}$, while Hybrid-Maize model (Yang et al., 2004) uses single-sine wave method with the same lower and upper thresholds.

Without knowing the error of estimated thermal time, directly citing each other's results could lead to biased decisions. The goal of this study is to analyze estimation error of thermal time derived from those six commonly used empirical linear methods based on daily temperatures. Unlike other similar studies, this analysis is based on a long-term dataset and focuses on the active corn growing season in Nebraska. We made two assumptions for this study, first, thermal time approximated with hourly temperatures is superior to that estimated with empirical linear methods based on daily temperature; second, these estimation errors are significant enough to be considered when being applied in corn production, such as predicting corn phenology, though observed corn phenology data would be needed in order to test this (Kumudini et al., 2014).

\section{Methodology}

The study area was the state of Nebraska, which is one of the main corn production states in the United States (USDA NASS, 2014; USDA NASS, 2015). Hourly averaged air temperature data were obtained from the High Plains Regional Climate Center's Automated Weather Data Network (AWDN) through the online Climate Data Services (http://www.hprcc.unl.edu/services, accessed 10 December 2015). These data were quality controlled by the HPRCC staff with a spatial regression test; the advantages of this test were stated by Hubbard and You (2005), Hubbard et al. (2007), and You et al. (2008). A combination standard of data completeness and corn production representativeness was used to choose the study locations. From the beginning year of record to year 2015, the maximum acceptable amount of missing data for each station for this study was set at $5 \%$. Missing data were replaced by reliable estimates, estimates based on weighted linear regression from surrounding stations, or unreliable estimates (HPRCC, 2015). Only two of the stations had no unreliable estimates of hourly temperature data, but that would be too few to represent the entire state's climate. Therefore, stations with up to $0.03 \%$ unreliable estimates were included in this study; these unreliable estimates were manually checked to ensure that they are climatologically reasonable. By consulting with local agronomists, a total of 14 observing stations $\left(40.08^{\circ}-42.47^{\circ} \mathrm{N}\right.$ and $96.48^{\circ}-101.72^{\circ} \mathrm{W}$, Fig. 1$)$ that are located in active corn production areas were chosen for the analysis. Depending on the station, the beginning year of study spans from 1982 to 1991 . The elevation of the stations ranges from 347 to $1029 \mathrm{~m}$. In this study, active corn growing season was defined as from May 1 to September 30 based on the USDA reports (USDA NASS Agricultural Statistics Board, 1997; USDA NASS, 2010). The obtained hourly temperature data were used to compute daily temperatures, including maximum, minimum, and average temperatures. During a 24 -hour period (i.e., from 0:00 to 23:59), the highest hourly temperature was considered as daily maximum temperature; the lowest hourly temperature was considered as daily minimum temperature; and the arithmetic mean of 
hourly temperature was considered as daily average temperature. This daily average temperature often differs from that derived from daily maximum and minimum temperatures alone.

In order to test the sensitivity of estimation methods to different temperature thresholds, three sets of lower and upper thresholds that are commonly used for corn were included in the analysis. They are: $8^{\circ}$ and $29^{\circ} \mathrm{C}$ (Butler and Huybers, 2012 ), $10^{\circ} \mathrm{C}$ (predominantly used by seed companies) and $30^{\circ} \mathrm{C}$ (McMaster and Wilhelm, 1997), as well as $8^{\circ}$ (used in crop models such as CERES-Maize and Hybrid-Maize) and $34^{\circ} \mathrm{C}$ (Kropff and van Laar, 1993). In addition to degree-days that are between lower and upper thresholds (i.e., $\mathrm{DD}_{8,29}, \mathrm{DD}_{10,30}, \mathrm{DD}_{8,34}$ ), the performance of different estimation methods on degree-days that are above upper thresholds (i.e., $\mathrm{DD}_{29+}, \mathrm{DD}_{30+}, \mathrm{DD}_{34+}$ ) were also analyzed in this study. Accumulated aboveupper-threshold temperatures have often been used to measure heat stress (Butler and Huybers, 2012; Lobell et al., 2011).

First, total growing season degree-days were calculated based on the observed hourly temperature data for each metric of thermal time at the study locations using Eqs. (2.1), (2.2), and (2.3), as described in Lobell et al. (2011):

$$
\begin{aligned}
& D D_{\text {lower,upper }}=\sum_{d=1}^{N} D D_{d} \\
& D D_{d}=\sum_{h=1}^{24} D D_{h} \\
& D D_{h}=\left\{\begin{array}{cc}
0 & \text { if } T_{\mathrm{h}}<T_{\text {lower }} \\
\left(T_{\mathrm{h}}-T_{\text {lower }}\right) / 24 & \text { if } T_{\text {lower }} \leq T_{\mathrm{h}}<T_{\text {upper }} \\
\left(T_{\text {upper }}-T_{\text {lower }}\right) / 24 & \text { if } T_{\mathrm{h}} \geq T_{\text {upper }}
\end{array}\right.
\end{aligned}
$$

Where $N$ is the number of days (153) for crop development over the growing season spanning from May

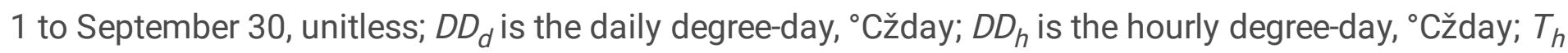
is the hourly temperature, ${ }^{\circ} \mathrm{C}$; $T_{\text {lower }}$ is the lower threshold, ${ }^{\circ} \mathrm{C}$; and $T_{\text {upper }}$ is the upper threshold, ${ }^{\circ} \mathrm{C}$.

Second, daily degree-days were estimated based on the calculated daily temperature data for each metric of thermal time at the study locations. A total of six estimation methods are evaluated in this study: $T_{\text {avg }}$ based rectangle method, adjusted $T_{\min }$ and $T_{\max }$ rectangle method, single-sine and double-sine methods with horizontal cut-off technique, and single triangulation and double triangulation methods with horizontal cut-off technique. For the two rectangle methods, Eqs. (2.4) and (2.5) were used to estimate daily degree-days, respectively. The detailed formulas to estimate daily degree-days for single-sine, double-sine, single-triangulation, and double-triangulation methods with horizontal cut-off technique are found at the UC IPM (2005). Eq. (2.1) was used to calculate total growing season degree-days for the six estimation methods.

$$
\begin{aligned}
& D D_{\text {lower,upper }}=T_{\text {avg_adj }}-T_{\text {lower }} \\
& D D_{\text {lower,upper }}=\frac{\left(T_{\text {max_adj } j}+T_{\text {min_adj })}\right.}{2}-T_{\text {lower }}
\end{aligned}
$$


Where $T_{\text {avg_adj }}$ is the adjusted daily average temperature, ${ }^{\circ} \mathrm{C} ; T_{\text {max_adj }}$ is the adjusted daily maximum temperature, ${ }^{\circ} \mathrm{C}$; and $T_{\text {min_adj }}$ is the adjusted daily minimum temperature, ${ }^{\circ} \mathrm{C}$. They are adjusted to lower threshold if they are below the lower threshold, and to upper threshold if they are above the upper threshold.

For the six metrics of thermal time analyzed in this study, degree-days approximated with hourly temperature was taken as true. The differences between degree-days estimated with daily temperature and degree-days approximated with hourly temperature were considered as errors. According to the recommendations from Chai and Draxler (2014), a combination of statistical metrics of root mean square error (RMSE) and mean absolute error (MAE) was used to assess the performance of different estimation methods. At every study location, Eqs. (2.6) and (2.7) were used to calculate RMSE and MAE for each metric of thermal time during the study period, respectively.

$$
\begin{aligned}
& \text { RMSE }=\sqrt{\frac{1}{n} \sum_{i=1}^{n} e_{i}{ }^{2}} \\
& M A E=\frac{1}{n} \sum_{i=1}^{n}\left|e_{i}\right|
\end{aligned}
$$

In these equations, $n$ is the number of total study years at the study location, unitless; $e_{i}$ is the error of total growing season degree-days, ${ }^{\circ} \mathrm{Czz}$ day.

\section{Results}

The analysis results are focused on three perspectives: first, the estimation errors of the six methods; second, comparison of estimated degree-days with true degree-days; and third, daily performance of the six estimation methods in extreme cool and warm years at the selected locations.

\subsection{Estimation errors of the six methods}

During the study period, the composite RMSE of total growing season degree-days for the six estimation methods at the 14 study locations ranged from 12.2 to $40.8^{\circ} \mathrm{C} z$ day for the three metrics of thermal time that were defined as between lower and upper thresholds, and from 0.6 to $60.2^{\circ} \mathrm{Czzday}$ for the three metrics of thermal time that were defined as above upper thresholds. Meanwhile, the composite MAE ranged from 10.5 to $34.7^{\circ} \mathrm{Cžday}$ for the three metrics of $\mathrm{DD}_{8,29}, \mathrm{DD}_{10,30}$, and $\mathrm{DD}_{8,34}$; and from 0.4 to $56.5^{\circ} \mathrm{Czzday}$ for the three metrics of $\mathrm{DD}_{29+}, \mathrm{DD}_{30+}$, and $\mathrm{DD}_{34+}$. For all six metrics of thermal time, the adjusted $T_{\min }$ and $T_{\max }$ rectangle method uniformly showed the greatest composite RMSE and MAE. By contrast, the single-sine method showed the smallest composite RMSE and MAE for $\mathrm{DD}_{8,29}$ and $\mathrm{DD}_{10,30}$; the $T_{\text {avg }}$-based rectangle method showed the smallest composite RMSE and MAE for $\mathrm{DD}_{8,34}$; and the double-sine method showed the smallest composite $\mathrm{RMSE}$ for $\mathrm{DD}_{29+}$ and $\mathrm{DD}_{30+\cdot}$. Both single-sine and double-sine methods showed the smallest composite RMSE and MAE for $\mathrm{DD}_{34+}$. 
At the majority of the study locations, the single-sine method showed the smallest estimation error for $\mathrm{DD}_{8,29}$ and $\mathrm{DD}_{10,30}$. The $T_{\text {avg }}$-based method showed the smallest RMSE (MAE) for $\mathrm{DD}_{8,34}$ at a total of 13 (12) out of the 14 study locations (Table 2). In other words, the single-sine method was sensitive to the lower and upper thresholds; it performed the best when the upper threshold was relatively low (e.g., 29 and $30^{\circ} \mathrm{C}$ ). When the upper threshold was relatively high (e.g., $\left.34^{\circ} \mathrm{C}\right)$, the $T_{\text {avg }}$-based method outperformed the single-sine method. For the three metrics of thermal time that were defined as above upper thresholds, the double-sine method uniformly showed the smallest estimation error at the majority of the study locations. For the adjusted $T_{\min }$ and $T_{\max }$ rectangle method, the smallest RMSE and MAE of total growing season degree-days for corn only occurred in two situations: $\mathrm{DD}_{8,29}$ at Elgin and $\mathrm{DD}_{10,30}$ at Holdrege.

Table 1

Composite RMSEs and MAEs (in parentheses) of total growing season degree-days for corn for the six estimation methods during the study period at the 14 study locations in Nebraska (unit: ${ }^{\circ} \mathrm{Czzday}$ ).

\begin{tabular}{|c|c|c|c|c|c|c|}
\hline Method & $\mathrm{DD}_{8,29}$ & $\mathrm{DD}_{10,30}$ & $\mathrm{DD}_{8,34}$ & $\mathrm{DD}_{29+}$ & $\mathrm{DD}_{30+}$ & $\mathrm{DD}_{34+}$ \\
\hline$T_{a v g}$-based & $\begin{array}{l}40.4 \\
(34.1)\end{array}$ & $\begin{array}{l}24.5 \\
(19.7)\end{array}$ & $\begin{array}{l}12.2 \\
(10.5)\end{array}$ & $\begin{array}{l}51.6 \\
(46.4)\end{array}$ & $\begin{array}{l}38.9 \\
(33.9)\end{array}$ & $8.2(6.0)$ \\
\hline $\begin{array}{l}\text { Adjusted } T_{\max } \text { and } \\
T_{\min }\end{array}$ & $\begin{array}{l}40.8 \\
(34.7)\end{array}$ & $\begin{array}{l}28.1 \\
(22.7)\end{array}$ & $\begin{array}{l}23.6 \\
(20.7)\end{array}$ & $\begin{array}{l}60.2 \\
(56.5)\end{array}$ & $\begin{array}{l}48.2 \\
(44.2)\end{array}$ & $\begin{array}{l}14.1 \\
(11.1)\end{array}$ \\
\hline Single-sine & $\begin{array}{l}17.2 \\
(14.3)\end{array}$ & $\begin{array}{l}17.7 \\
(14.9)\end{array}$ & $\begin{array}{l}18.5 \\
(15.6)\end{array}$ & $3.9(3.3)$ & $2.9(2.4)$ & $0.6(0.4)$ \\
\hline Double-sine & $\begin{array}{l}17.5 \\
(14.6)\end{array}$ & $\begin{array}{l}18.0 \\
(15.1)\end{array}$ & $\begin{array}{l}18.9 \\
(15.9)\end{array}$ & $3.8(3.2)$ & $2.8(2.3)$ & $0.6(0.4)$ \\
\hline Single-triangulation & $\begin{array}{l}23.3 \\
(20.2)\end{array}$ & $\begin{array}{l}21.0 \\
(17.7)\end{array}$ & $\begin{array}{l}18.8 \\
(15.4)\end{array}$ & $\begin{array}{l}15.5 \\
(14.2)\end{array}$ & $\begin{array}{l}12.6 \\
(11.1)\end{array}$ & $3.7(2.7)$ \\
\hline Double-triangulation & $\begin{array}{l}23.9 \\
(20.9)\end{array}$ & $\begin{array}{l}21.5 \\
(18.1)\end{array}$ & $\begin{array}{l}19.2 \\
(15.7)\end{array}$ & $\begin{array}{l}15.7 \\
(14.3)\end{array}$ & $\begin{array}{l}12.7 \\
(11.3)\end{array}$ & $3.7(2.7)$ \\
\hline
\end{tabular}


Table 2

Numbers of study locations that show the smallest RMSE and MAE (in parentheses) of total growing season degree-days for corn for the six estimation methods during the study period in Nebraska.

\begin{tabular}{|lllllll|}
\hline Method & $\mathrm{DD}_{8,29}$ & $\mathrm{DD}_{10,30}$ & $\mathrm{DD}_{\mathbf{8 , 3 4}}$ & $\mathrm{DD}_{29+}$ & $\mathrm{DD}_{30+}$ & $\mathrm{DD}_{34+}$ \\
\hline$T_{\text {avg }}$-based & $0(0)$ & $3(3)$ & $13(12)$ & $0(0)$ & $0(0)$ & $0(0)$ \\
\hline Adjusted $T_{\max }$ and $T_{\min }$ & $1(1)$ & $1(1)$ & $0(0)$ & $0(0)$ & $0(0)$ & $0(0)$ \\
\hline Single-sine & $8(9)$ & $5(6)$ & $0(0)$ & $4(4)$ & $4(4)$ & $4(5)$ \\
\hline Double-sine & $2(0)$ & $4(3)$ & $1(2)$ & $10(10)$ & $10(10)$ & $10(9)$ \\
\hline Single-triangulation & $2(3)$ & $1(1)$ & $0(0)$ & $0(0)$ & $0(0)$ & $0(0)$ \\
\hline Double-triangulation & $1(1)$ & $0(0)$ & $0(0)$ & $0(0)$ & $0(0)$ & $0(0)$ \\
\hline
\end{tabular}

\subsection{Comparison of estimated degree-days with true degree-days}

During the study period, estimated total growing season degree-days with the adjusted $T_{\max }$ and $T_{\min }$ rectangle method uniformly showed the largest deviation from that approximated with the observed hourly temperature data for the three metrics of thermal time that were defined as between lower and upper thresholds. In particular, this method performed the worst for total growing season $\mathrm{DD}_{8,29}$ (Fig. 2(a)), and the deviation was caused by overestimation of the relatively small values and underestimation of the relatively large values. Meanwhile, estimated total growing season degree-days with the single-sine method showed the smallest deviation from that approximated with the observed hourly temperature data for both $\mathrm{DD}_{8,29}$ and $\mathrm{DD}_{10,30}$. Especially, the single-sine method performed the best for total growing season $\mathrm{DD}_{8,29}$ (Fig. 2(b)). Meanwhile, the $T_{\text {avg }}$-based rectangle method showed the smallest deviation for total growing season $\mathrm{DD}_{8,34}$ (Fig. 3(b)). As compared with degree-days approximated with the observed hourly temperature data, the six estimation methods showed a similar performance pattern for the three metrics of thermal time that were defined as above upper thresholds: the $T_{\text {avg }}$-based rectangle method drastically underestimated, the adjusted $T_{\max }$ and $T_{\min }$ rectangle method largely overestimated, the single-sine and double-sine methods provided the best estimation, and the single-triangulation and double-triangulation methods tended to underestimate (Fig. 4). Moreover, during relatively warm growing seasons, the adjusted $T_{\max }$ and $T_{\min }$ rectangle method overestimated the three metrics of $\mathrm{DD}_{29+}, \mathrm{DD}_{30+}$, and $\mathrm{DD}_{34+}$ to a greater extent (Fig. $4(\mathrm{~b})$ ); the single- and doubletriangulation methods underestimated the three metrics of $\mathrm{DD}_{29+}, \mathrm{DD}_{30+}$, and $\mathrm{DD}_{34+}$ to a greater extent (Fig. 4(e), (f)).

\subsection{Selected cases in the extreme cool and warm years}

Based on the mean growing season average temperature during the study period, we identified the extreme cool and warm years at the 14 study locations in Nebraska (Table 3). During these extreme cool 
and warm years, the six estimation methods showed an inverse pattern in total growing season degreedays for corn that were defined as between lower and upper thresholds (Figs. 5 and 6 ). At the majority of the study locations, the $T_{\text {avg }}$-based method underestimated the three metrics of $\mathrm{DD}_{8,29}, \mathrm{DD}_{10,30}$, and $\mathrm{DD}_{8}$, ${ }_{34}$ in extreme cool years but overestimated them in extreme warm years. The opposite held true for the adjusted $T_{\max }$ and $T_{\min }$ rectangle method, single-sine and double-sine methods, which overestimated the three metrics of $\mathrm{DD}_{8,29}, \mathrm{DD}_{10,30}$, and $\mathrm{DD}_{8,34}$ in extreme cool years and underestimated them in extreme warm years. For single- and double-triangulation methods, this inverse pattern between extreme cool and warm years was relatively weak due to the internal inconsistency in estimation performance. In extreme cool years, the single- and double-triangulation methods underestimated $\mathrm{DD}_{8,29}$ at half of the study locations, and underestimated $\mathrm{DD}_{10,30}$ and $\mathrm{DD}_{8,34}$ at $57 \%$ of the study locations. In extreme warm years, the single- and double-triangulation methods overestimated $\mathrm{DD}_{8,29}$ and $\mathrm{DD}_{10,30}$ but underestimated $\mathrm{DD}_{8}$, 34 at the majority of the study locations.

Table 3

Years and mean growing season average temperatures (in parentheses, unit: ${ }^{\circ} \mathrm{C}$ ) for the extreme cool and warm years during the study period at the 14 study locations in

Nebraska.

\begin{tabular}{|lll|}
\hline Location & Extreme cool year & Extreme warm year \\
\hline Beatrice & $1992(19.7)$ & $2012(22.6)$ \\
\hline Champion & $1993(17.9)$ & $2012(21.3)$ \\
\hline Concord & $1985(17.7)$ & $1988(21.2)$ \\
\hline Curtis & $1992(18.5)$ & $2012(22.2)$ \\
\hline Dickens & $1993(17.5)$ & $2012(21.4)$ \\
\hline Elgin & $1992(17.9)$ & $2012(21.0)$ \\
\hline Havelock & $1992(19.4)$ & $2012(23.5)$ \\
\hline Holdrege & $1992(18.7)$ & $2012(21.6)$ \\
\hline McCook & $1992(18.8)$ & $2012(22.4)$ \\
\hline Mead & $1992(19.2)$ & $1988(22.4)$ \\
\hline North Platte & $1992(17.8)$ & $2012(21.7)$ \\
\hline O'Neill & $1992(17.4)$ & $2012(21.5)$ \\
\hline Ord & $1992(18.3)$ & $1988(21.8)$ \\
\hline Red Cloud & $1992(19.4)$ & $2000(24.0)$ \\
\hline
\end{tabular}


In extreme cool years, the $T_{\text {avg }}$-based rectangle method showed the smallest composite MAE for $D_{8,29}$ and $\mathrm{DD}_{8,34}$, and the single-sine method showed the smallest composite $\mathrm{MAE}$ for $\mathrm{DD}_{10,30}$. In extreme warm years, the single-sine method showed the smallest composite $M A E$ for $D_{8,29}$ and $D_{10,30}$, and the $T_{\text {avg }}$-based rectangle method showed the smallest composite MAE for $\mathrm{DD}_{8,34}$. By contrast, the adjusted $T_{\max }$ and $T_{\min }$ rectangle method showed the greatest composite MAE for the three metrics of $D_{8,29}$, $\mathrm{DD}_{10,30}$, and $\mathrm{DD}_{8,34}$ in both extreme cool and warm years, with the exception of $\mathrm{DD}_{8,29}$ in extreme cool years. In extreme cool years, the double-triangulation method showed the greatest composite MAE for $\mathrm{DD}_{8,29}$. Among all the estimations for the three metrics of $\mathrm{DD}_{8,29}, \mathrm{DD}_{10,30}$, and $\mathrm{DD}_{8,34}$ in extreme years, the adjusted $T_{\max }$ and $T_{\min }$ rectangle method was the worst to estimate $\mathrm{DD}_{8,29}$ in extreme warm years, with an underestimation error ranging from 36.3 to $118.0^{\circ}$ Cžday (Fig. 6(a)).

In extreme cool and warm years, the six methods showed similar predominant patterns in estimation performance for the three metrics of thermal time that were defined as above upper thresholds in Nebraska. At the majority of the study locations, the $T_{\text {avg }}$-based rectangle method underestimated the three metrics of $\mathrm{DD}_{29+}, \mathrm{DD}_{30+}$, and $\mathrm{DD}_{34+}$ in both extreme cool and warm years; the adjusted $T_{\max }$ and $T_{\text {min }}$ rectangle method overestimated them in both extreme cool and warm years; the single- and doublesine methods overestimated them in both extreme cool and warm years; and the single- and doubletriangulation methods underestimated them in both extreme cool and warm years (Figs. 7 and 8). Among the six methods, the double-sine method showed the smallest composite MAE for the three metrics of $\mathrm{DD}_{29+}, \mathrm{DD}_{30+}$, and $\mathrm{DD}_{34+}$ in extreme years; and the adjusted $T_{\max }$ and $T_{\min }$ rectangle method showed the greatest composite MAE for the three metrics of $D^{29+}, D_{30+}$, and $D^{2} D_{34+}$ in extreme years. In extreme cool years, all six methods estimated $\mathrm{DD}_{34+}$ as zero at the three locations of Havelock, Elgin, and Red Cloud, which matched the results that were approximated from the observed hourly temperature data (Fig. 7(c)).

In addition, four cases were selected to present how the six methods performed on a daily timescale during the growing season in extreme years. For the three metrics of thermal time that were defined as between lower and upper thresholds, the two cases that had the greatest total absolute errors were: $\mathrm{DD}_{8}$, 34 at Concord in 1985 (extreme cool year) and $D_{8,29}$ at Red Cloud in 2000 (extreme warm year). During the extreme cool year at Concord, all six methods underestimated total growing season $\mathrm{DD}_{8,34}$; among them, the $T_{\text {avg }}$-based rectangle method showed the smallest estimation error and the estimation error remained steady throughout the growing season, while the double-triangulation method showed the greatest estimation error and the estimation error increased with time during the growing season (Fig. 9(a)). During the extreme warm year at Red Cloud, the $T_{\text {avg }}$-based rectangle method showed the greatest overestimation error and the overestimation error increased with time during the growing season; the adjusted $T_{\max }$ and $T_{\min }$ rectangle method showed the greatest underestimation error and the underestimation error increased with time during the growing season (Fig. 9(b)). For the three metrics of thermal time that were defined as above upper thresholds, the two cases that had the greatest total absolute errors were $\mathrm{DD}_{29+}$ at McCook in 1992 (extreme cool year) and $\mathrm{DD}_{29+}$ at Champion in 2012 
(extreme warm year). During the extreme years at McCook and Champion, the six methods showed similar performance: the $T_{\text {avg }}$-based rectangle method and both the single- and double-triangulation methods underestimated, while the adjusted $T_{\max }$ and $T_{\min }$ rectangle method and both the single- and double-sine methods overestimated. Among which the $T_{\text {avg }}$-based method showed the greatest underestimation error as would be expected, in particular, the $T_{\text {avg }}$-based method estimated daily $\mathrm{DD}_{29+}$ as zero throughout the growing season at McCook in the extreme cool year. Meanwhile, the adjusted $T_{\max }$ and $T_{\min }$ rectangle method showed the greatest overestimation error, and this overestimation error increased over time during the growing season. Both of the single- and double-sine methods performed well in the early growing season, but started to overestimate in the middle-to-late growing season. Both of the single- and double-triangulation methods underestimated and the error increased with time, especially in the second half of the growing season (Fig. 10).

\section{Conclusions}

At the 14 study locations in Nebraska, the single- and double-sine methods were generally the best to estimate thermal time for corn during the growing season, with an exception of $\mathrm{DD}_{8,34}$ that was best estimated by the $T_{\text {avg }}$-based rectangle method. This implies that the single- and double-sine methods were sensitive to the lower and upper thresholds. Though being the most widely used method in corn production in the study area, the adjusted $T_{\max }$ and $T_{\min }$ rectangle method showed the greatest composite RMSE and MAE for all six metrics of thermal time. We conclude that the adjusted $T_{\max }$ and $T_{\text {min }}$ rectangle method was not ideal for estimating growing season thermal time for corn in Nebraska. When citing the growing season degree-days for corn that was computed with the $T_{\min }$ and $T_{\max }$ rectangle method, it is crucial to check the accuracy.

At the majority of the study locations, the adjusted $T_{\max }$ and $T_{\min }$ rectangle method overestimated the three metrics of $\mathrm{DD}_{8,29}, \mathrm{DD}_{10,30}$ and $\mathrm{DD}_{8,34}$ in extreme cool years but underestimated them in extreme warm years; the single- and double-sine methods tended to overestimate the three metrics of $\mathrm{DD}_{8,29}$, $\mathrm{DD}_{10,30}$ and $\mathrm{DD}_{8,34}$ in extreme cool years but underestimate them in extreme warm years. In both extreme cool and warm years, the adjusted $T_{\max }$ and $T_{\min }$ rectangle method showed the greatest composite MAE. In particular, the six studied estimation methods performed the worst for $\mathrm{DD}_{8,34}$ at Concord in extreme cool year and $\mathrm{DD}_{8,29}$ at Red Cloud in extreme warm year. At Concord, all six methods uniformly underestimated total growing season $\mathrm{DD}_{8,34}$ in the extreme cool year of the study period. In the extreme warm year of the study period at Red Cloud, the $T_{\text {avg }}$-based rectangle method showed the greatest overestimation error for total growing season $\mathrm{DD}_{8,29}$; the adjusted $T_{\max }$ and $T_{\min }$ rectangle method showed the greatest underestimation error for total growing season $\mathrm{DD}_{8,29}$; and these two daily overestimation and underestimation errors increased with time within the growing season.

For the three metrics of thermal time that were defined as above upper thresholds, the six methods performed similar dominant patterns in extreme cool and warm years. At the majority of the study 
locations, the $T_{\text {avg }}$-based rectangle method and single- and double-triangulation methods tended to underestimate the three metrics of $\mathrm{DD}_{29+}, \mathrm{DD}_{30+}, \mathrm{DD}_{34+}$; while the adjusted $T_{\max }$ and $T_{\min }$ rectangle method and single- and double-sine methods tended to overestimate. In both extreme cool and warm years, the double-sine method showed the smallest MAE for the three metrics of $D^{29+}, D_{30+}, D_{34+}$, while the adjusted $T_{\max }$ and $T_{\min }$ rectangle method showed the greatest MAE. The six studied methods performed the worst for $\mathrm{DD}_{29+}$ at McCook in extreme cool years and $\mathrm{DD}_{29+}$ at Champion in extreme warm years. In particular, the adjusted $T_{\max }$ and $T_{\min }$ rectangle method overestimated in both of the two cases, and this overestimation error became worse over time within the growing season for corn.

For the three metrics of thermal time that were defined as between lower and upper thresholds, the recommended methods could be used by corn producers to choose the varieties to replant to compensate for the loss of the emerged corn plants in early growing season when destroying weather events occur and replanting is still an option. For the three metrics of thermal time that were defined as above upper threshold, the recommended methods could provide high-accuracy degree-days to quantify the potential heat stress for corn plants. The adjusted $T_{\max }$ and $T_{\min }$ rectangle method, though being used the most in the study area, is not recommended to estimate total growing season degree-days for corn with daily temperature data. In particular, the adjusted $T_{\max }$ and $T_{\min }$ rectangle method overestimated the three metrics of $\mathrm{DD}_{8,29}, \mathrm{DD}_{10,30}$ and $\mathrm{DD}_{8,34}$ in extreme cool years but underestimated them in extreme warm years at the study locations. The adjusted $T_{\max }$ and $T_{\min }$ rectangle method was found to overestimate the three metrics of $\mathrm{DD}_{29+}, \mathrm{DD}_{30+}, \mathrm{DD}_{34+}$ in both extreme cool and warm years at the study locations; furthermore, this overestimation tended to worsen with time within the growing season. However, the 14 study locations may not fully cover the climate regime in the entire corn-growing area in Nebraska. Therefore, additional verifications would be necessary before applying these recommendations to other corn-belt states.

\section{Declarations}

\section{Conflict of Interest:}

We declare that there are no known conflicts of interest associated with this publication and there has been no significant financial support for this work that could have influenced its outcome.

\section{Funding Statement:}

This study was supported by Agriculture and Food Research Initiative Competitive Grant no. 2011-6800230220 from the USDA National Institute of Food and Agriculture. The publication of this study is supported by University of Nebraska-Lincoln and the Nebraska State Climate Office.

\section{Author's Contribution:}


Shuwei Dai conceived of the presented idea and performed the computations. Martha D. Shulski contributed to data analyses and the results interpretation. Haishun Yang contributed to the analytical methods verification and provided critical feedback. Roger W. Elmore contributed to the location selection and helped shape the analysis. Shuwei Dai wrote the manuscript in consultation with Martha D. Shulski, Haishun Yang, and Roger W. Elmore. All authors discussed the results and contributed to the final manuscript.

\section{Availability of data and material:}

The data and material will be available to the readers upon request only.

\section{Code availability:}

The custom code is not available to the readers.

\section{Ethics approval:}

Not applicable.

\section{Consent to participate:}

Not applicable.

\section{Consent for publication:}

Not applicable.

\section{References}

1. Allen JC (1976) A modified sine wave method for calculating degree days. Environ. Entomol. 5: 388396.

2. Arnold CY (1960) Maximum-minimum temperatures as a basis for computing heat units. J. Am. Soc. Hortic. Sci. 76: 682-692.

3. Baskerville GL, Emin P (1969) Rapid estimation of heat accumulation from maximum and minimum temperatures. Ecology 50: 514-517.

4. Bigelow FH (1909) Report on the temperatures and vapor tensions of the United States reduced to a homogenous system of 24 hourly observations for the 33-year interval, 1873-1905. U.S. Department of Agriculture Weather Bureau Bulletin S. Washington: Government Printing Office.

5. Butler EE, Huybers P (2012) Adaptation of US maize to temperature variations. Nat. Clim. Chang. 3: 68-72.

6. Chai T, Draxler RR (2014) Root mean square error (RMSE) or mean absolute error (MAE)? Arguments against avoiding RMSE in the literature. Geosci. Model Dev. 7: 1247-1250. 
7. Cross HZ, Zuber MS (1972) Prediction of flowering dates in maize based on different methods of estimating thermal units. Agron. J. 64: 351-355.

8. Feng S, Hu Q (2004) Changes in agro-meteorological indicators in the contiguous United States: 1951-2000. Theor. Appl. Climatol. 78: 247-264.

9. Gilmore EC Jr., Rogers JS (1958) Heat units as a method of measuring maturity in corn. Agron. J. 50: 611-615.

10. High Plains Regional Climate Center (2015) Flags on Data and What they Mean. http://hprcc6.unl.edu/online/help/FlagHelp.html (accessed 3 March 2015).

11. Hubbard KG, Guttman NB. You J, Chen Z (2007) An improved QC process for temperature in the daily cooperative weather observations. J. Atmos. Oceanic Technol. 24: 206-213.

12. Hubbard KG, You J (2005) Sensitivity analysis of quality assurance using the spatial regression approach - A case study of the maximum/minimum air temperature. J. Atmos. Oceanic Technol. 22: $1520-1530$.

13. Jones CA, Kiniry JR (1986) CERES-Maize: A simulation model of maize growth and development. Texas A\&M University Press: College Station, Texas USA.

14. Kropff MJ, van Laar HH (1993) Modelling crop-weed interactions. CAB International in association with the International Rice Research Institute: Wallingford, UK.

15. Kumudini S, Andrade FH, Boote KJ, Brown GA, Dzotsi KA, Edmeades GO, Gocken T, Goodwin M, Halter AL, Hammer GL, Hatfield JL, Jones JW, Kemanian AR, Kim S-H, Kiniry J, Lizaso I, Nendel C, Nielsen RL, Parent B, Stöckle CO, Tardieu F, Thomison PR, Timlin DJ, Vyn TJ, Wallach D, Yang H, Tollenaar M (2014) Predicting maize phenology: Intercomparison of functions for developmental response to temperature. Agron. J. 106: 2087-2097.

16. Lindsey AA, Newman JE (1956) Use of official weather data in spring time-temperature analysis of an Indiana phenological record. Ecology 37: 812-823.

17. Lobell DB, Bänziger M, Magorokosho C, Vivek B (2011) Nonlinear heat effects on African maize as evidenced by historical yield trials. Nat. Clim. Chang. 1: 42-45.

18. McMaster GS, Wilhelm WW (1997) Growing degree-days: one equation, two interpretations. Agric. For. Meteorol. 87: 291-300.

19. Neild RE (1967) Maximum-minimum temperatures as a basis for evaluating thermoperiodic response. Mon. Weather Rev. 95: 583-584.

20. Roltsch WJ, Zalom FG, Strawn AJ, Strand JF, Pitcairn MJ (1999) Evaluation of several degree-day estimation methods in California climates. Int. J. Biometeorol. 42: 169-176.

21. Russelle MP, Wilhelm W, Olson RA, Power JF (1984) Growth analysis based on degree days. Crop Sci. 24: 28-32.

22. Sevacherian V, Stern VM, Mueller AJ (1977) Heat accumulation for timing Lygus control measures in a safflower-cotton complex. J. Econ. Entomol. 70: 399-402. 
23. University of California Statewide Integrated Pest Management Program (UC IPM) (2005) How to Manage Pests: Degree-days: Methods. http://www.ipm.ucdavis.edu/WEATHER/ddfigindex.html (accessed 10 June 2015).

24. U.S. Department of Agriculture National Agricultural Statistics Service, Agricultural Statistics Board (1997) Usual planting and harvesting dates for U.S. field crops. Agricultural Handbook Number 628.

25. U.S. Department of Agriculture National Agricultural Statistics Service (2010) Field crops usual planting and harvesting dates. Agricultural Handbook Number 628, pp. 9.

26. U.S. Department of Agriculture National Agricultural Statistics Service (2014). 2012 Census of Agriculture Nebraska State and County Data. Volume 1, Geographic Area Series, Part 27, pp. 8.

27. U.S. Department of Agriculture National Agricultural Statistics Service (2015) 2014 State Agriculture Overview. http://www.nass.usda.gov/Quick_Stats/Ag_Overview/stateOverview.php? state=NEBRASKA (accessed 19 June, 2015).

28. Yang H, Dobermann A, Lindquist JL, Walters DT, Arkebauer TJ, Cassman KG (2004) Hybrid-maize - a maize simulation model that combines two crop modeling approaches. Field Crop. Res. 87: 131154.

29. You J, Hubbard KG, Goddard S (2008) Comparison of methods for spatially estimating station temperatures in a quality control system. Int. J. Climatol. 28: 777-787.

30. Zalom FG, Goodell PB, Wilson LT, Barnett WW, Bentley WJ (1983) Degree-days: calculation and use of heat units in pest management. University of California, Division of Agriculture and Natural Resources, Leaflet 21373, pp.10.

\section{Figures}




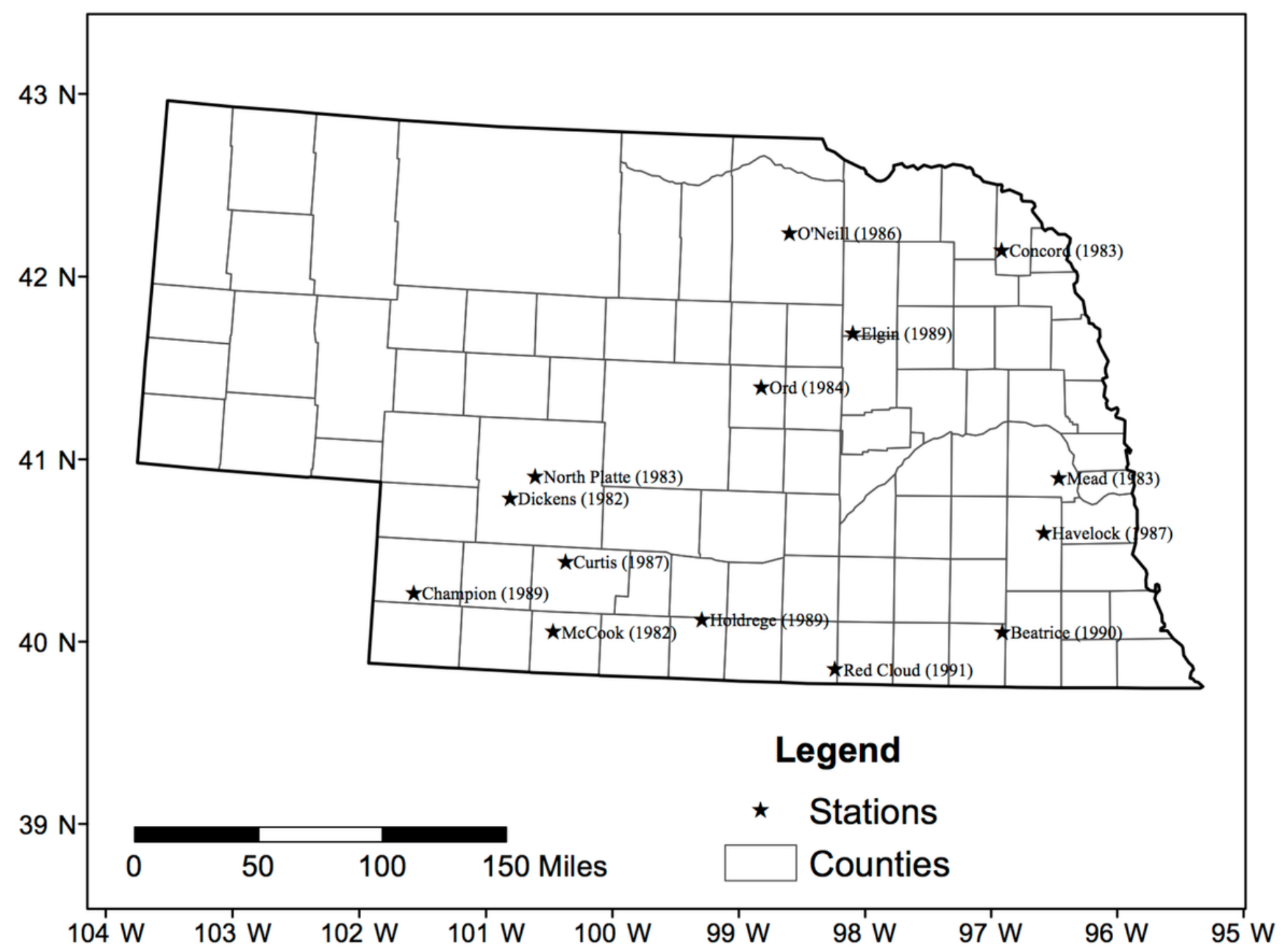

Figure 1

Locations of the 14 meteorological stations in Nebraska, U.S.. The beginning year of study for each location is included in parentheses after the name of the station. 

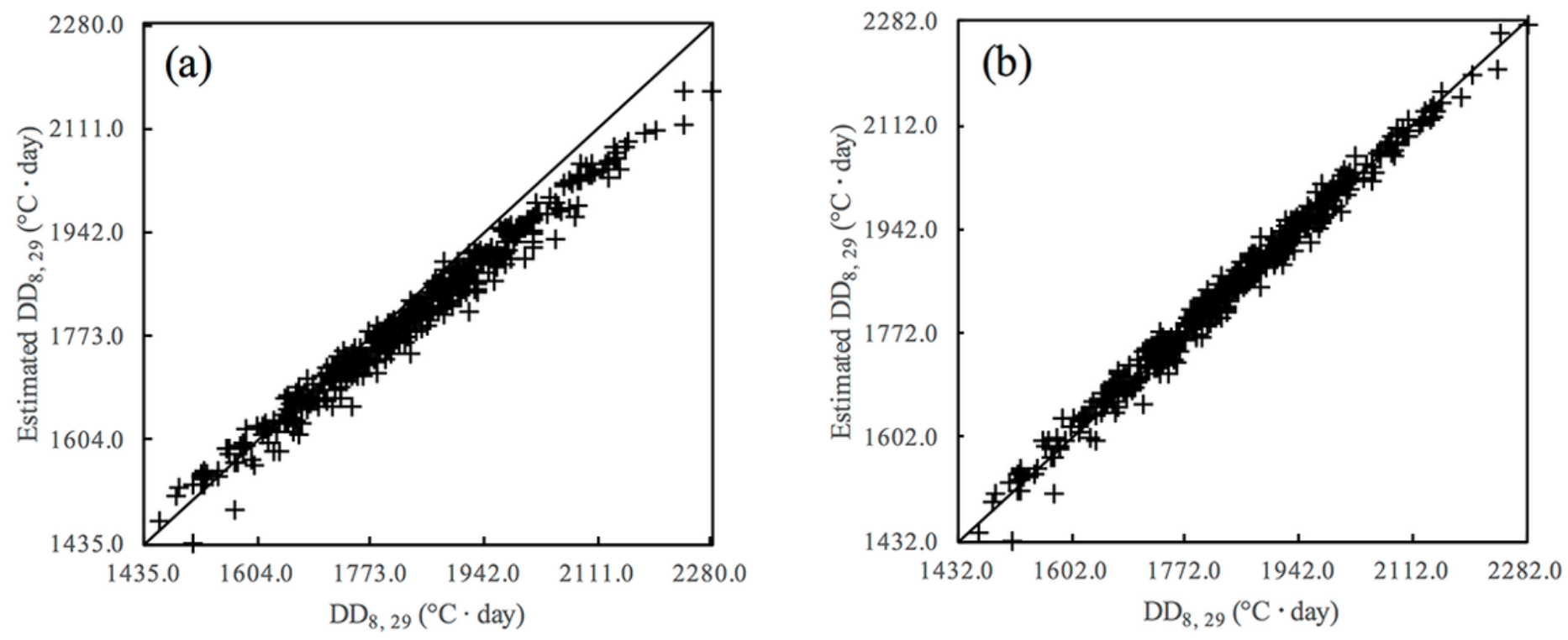

Figure 2

Comparison of estimated total growing season DD8, 29 with (a) the adjusted Tmax and Tmin rectangle method and (b) the single-sine method with approximated total growing season DD8, 29 based on the observed hourly temperature data during the study period at the 14 study locations in Nebraska.
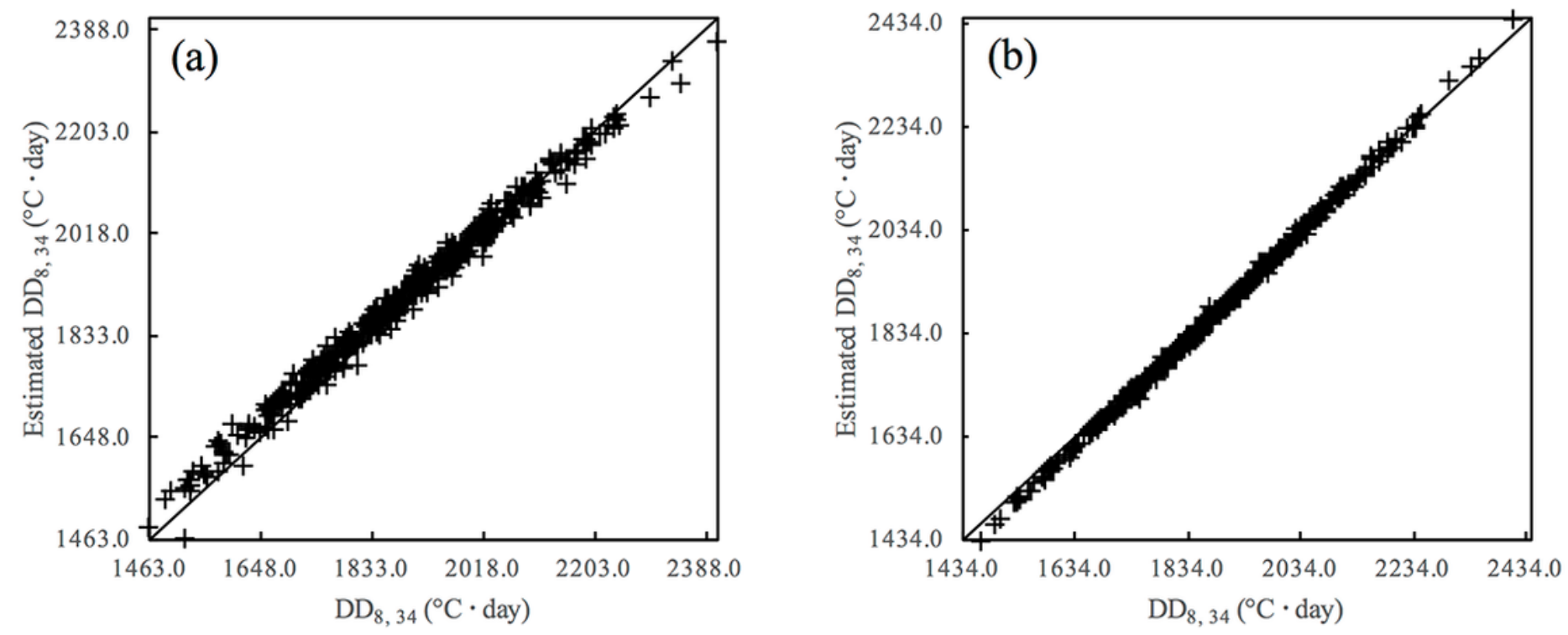

Figure 3

Comparison of estimated total growing season DD8, 34 with (a) the adjusted Tmax and Tmin rectangle method and (b) the Tavg-based rectangle method with approximated total growing season DD8, 34 based on the observed hourly temperature data during the study period at the 14 study locations in Nebraska. 

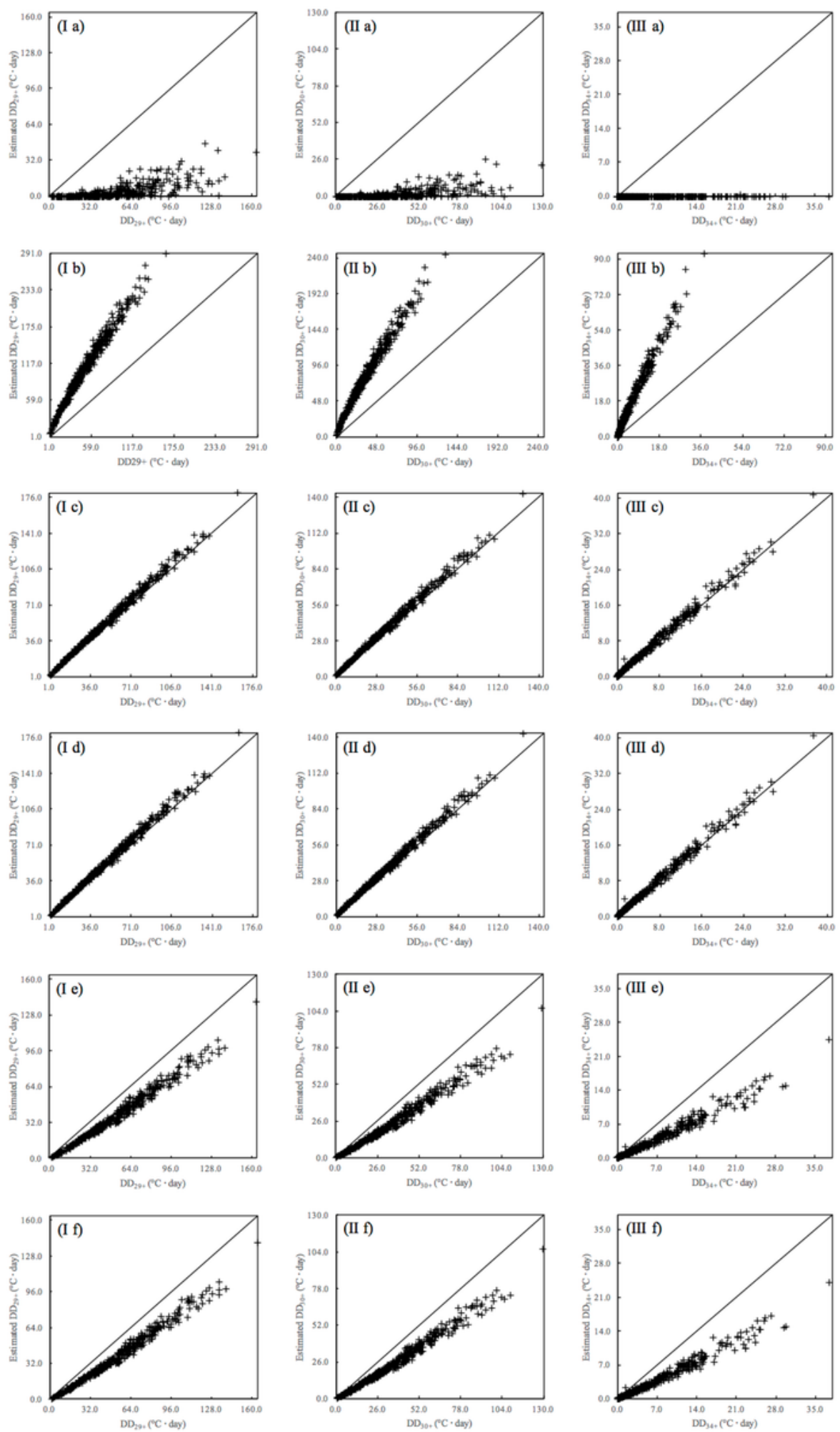

Figure 4

Comparison of estimated total growing season degree-days with the six methods with approximated total growing season degree-days based on the observed hourly temperature data during the study period at the 14 study locations in Nebraska. (I) DD29+. (II) DD30+. (III) DD34+. (a) The Tavg-based rectangle method. (b) The adjusted Tmax and Tmin rectangle method. (c) The single-sine method. (d) The doublesine method. (e) The single-triangulation method. (f) The double-triangulation method. 

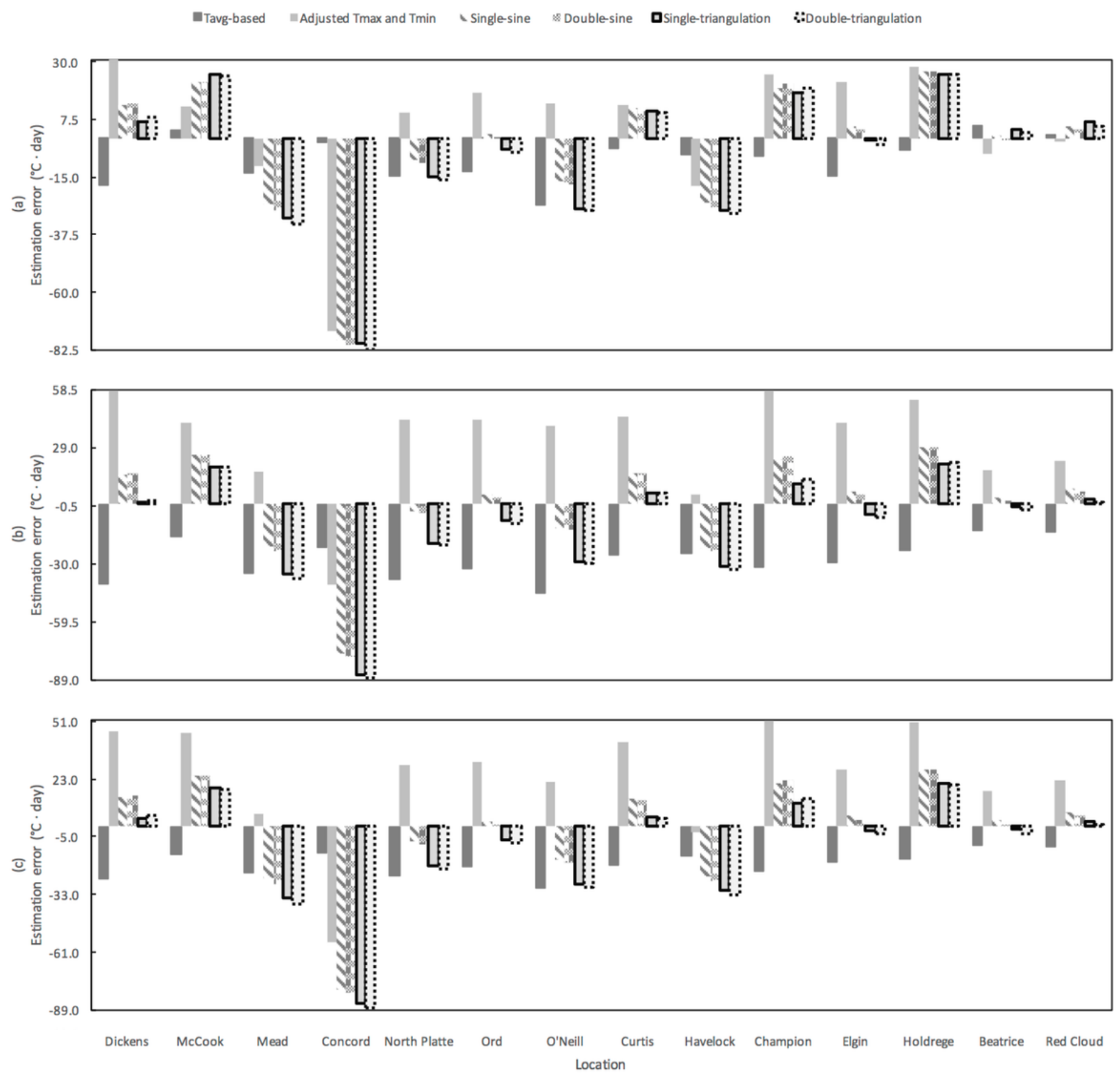

Figure 5

Estimation errors of the six methods in total growing season degree-days in extreme cool years for the 14 study locations in Nebraska. (a) DD8, 29. (b) DD10, 30. (c) DD8, 34. 

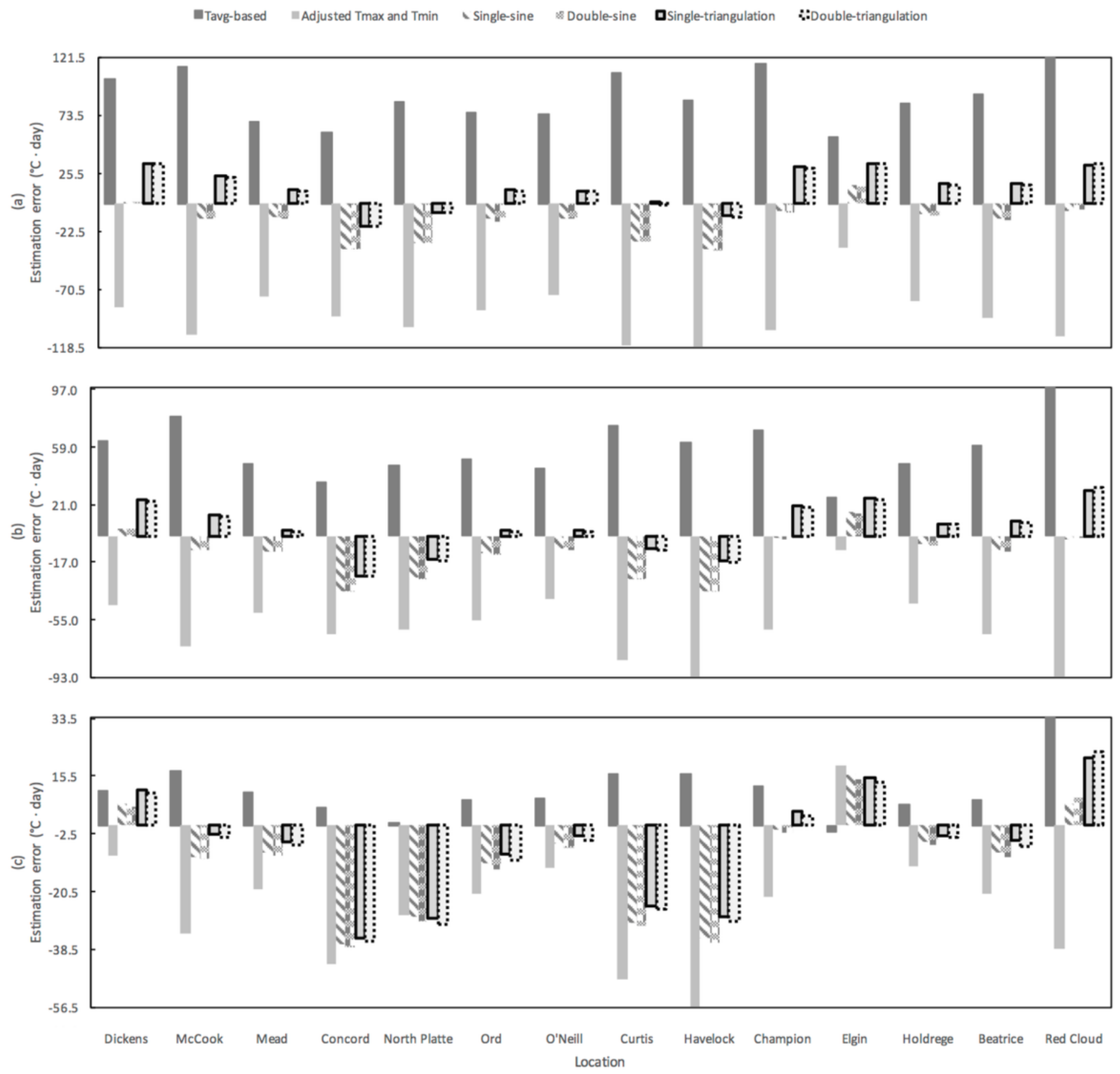

Figure 6

Estimation errors of the six methods in total growing season degree-days in extreme warm years for the 14 study locations in Nebraska. (a) DD8, 29. (b) DD10, 30. (c) DD8, 34. 

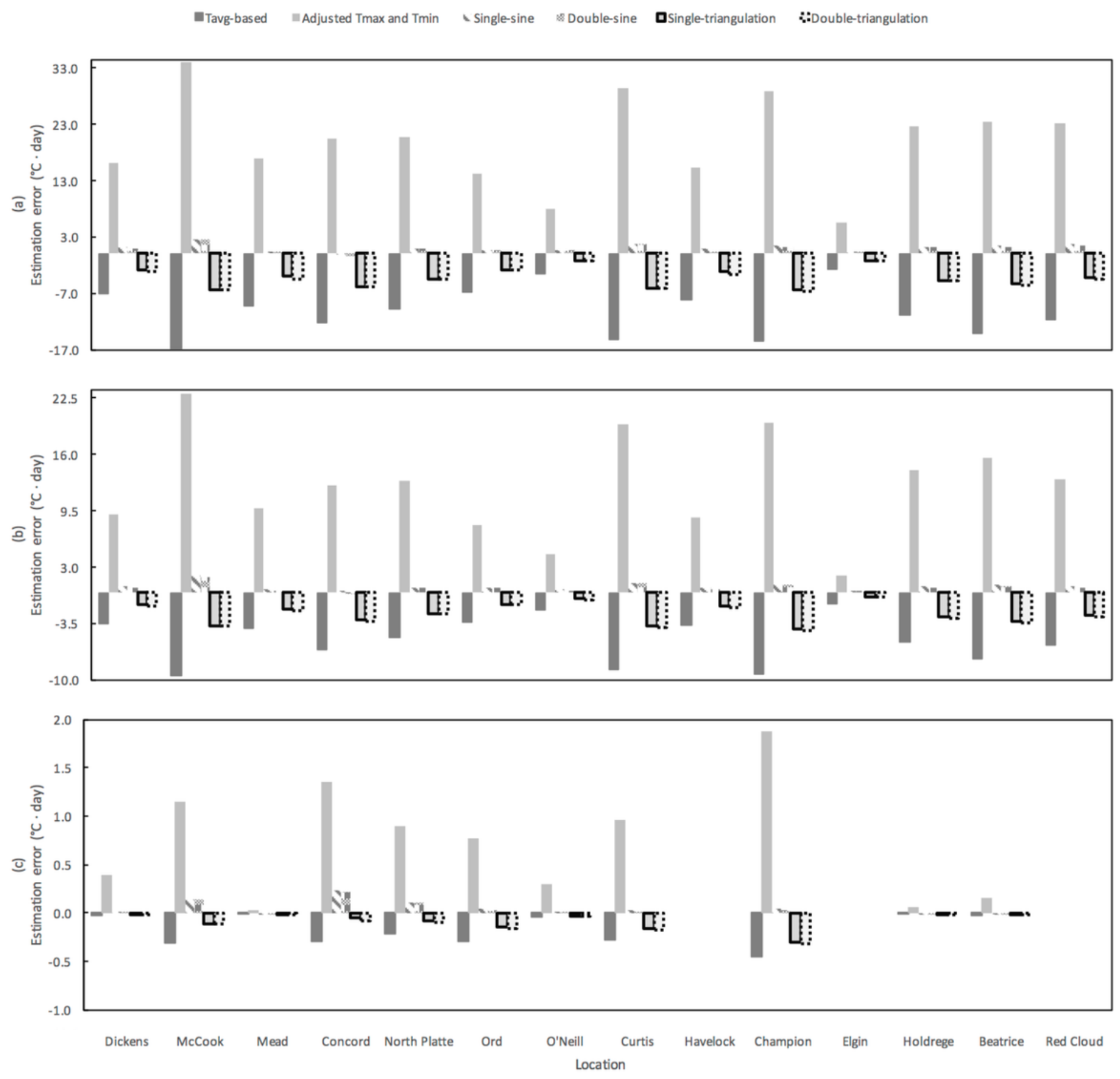

Figure 7

Estimation errors of the six methods in total growing season degree-days in extreme cool years for the 14 study locations in Nebraska. (a) DD29+. (b) DD30+. (c) DD34+. 

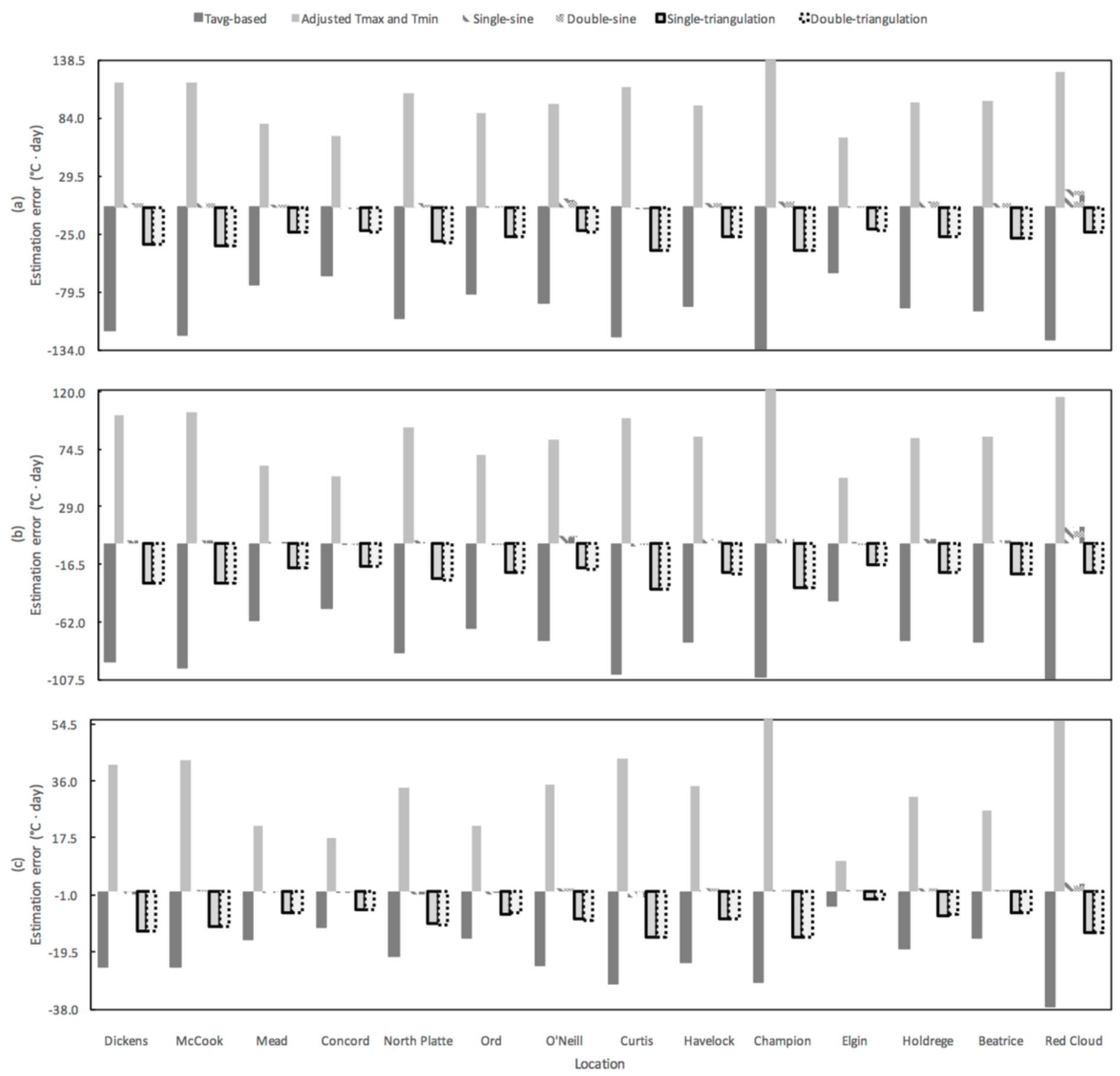

Figure 8

Estimation errors of the six methods in total growing season degree-days in extreme warm years for the 14 study locations in Nebraska. (a) DD29+. (b) DD30+. (c) DD34+. 

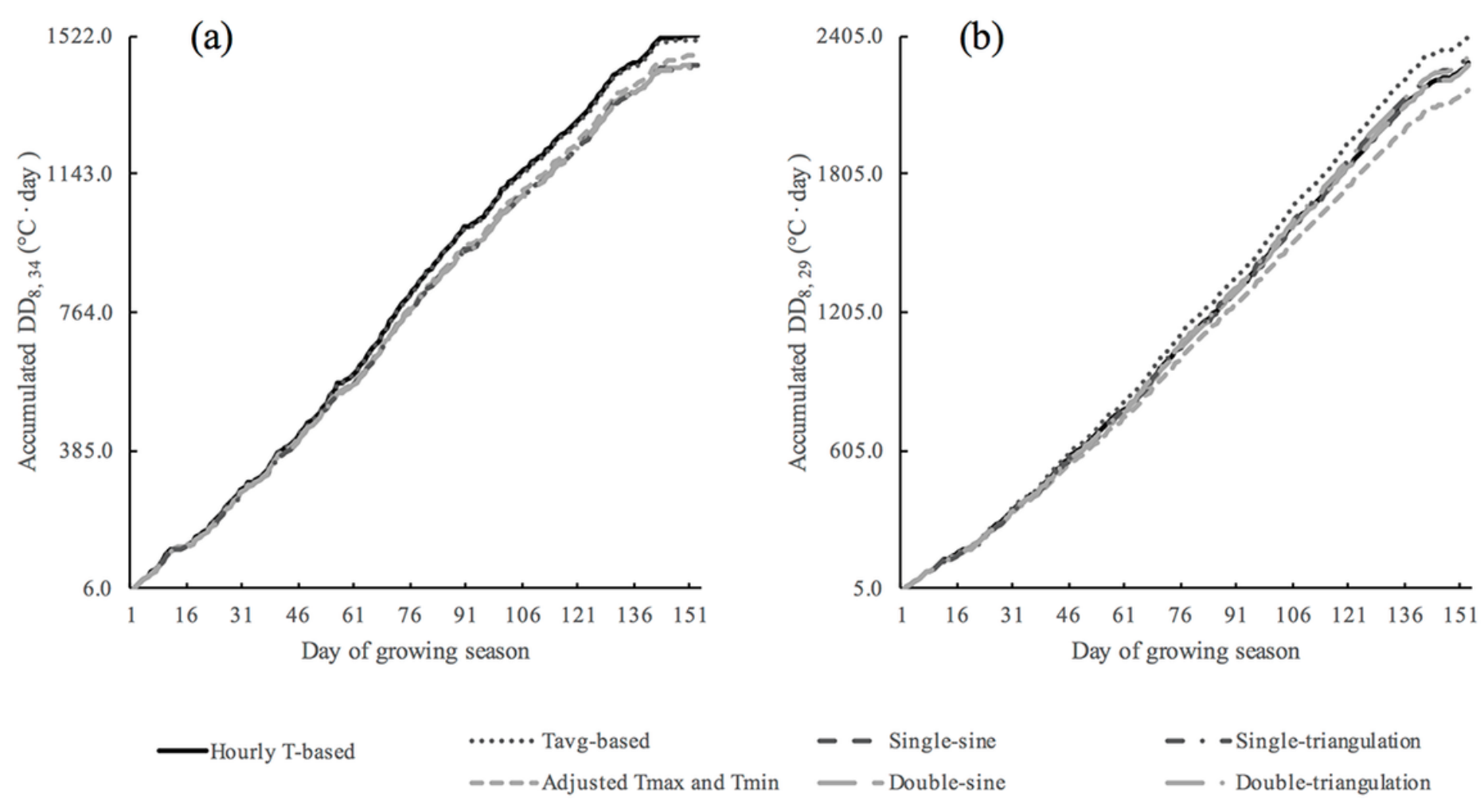

\section{Figure 9}

Accumulated degree-days within the growing season of extreme years at particular locations. (a) DD8, 34 at Concord, NE in the extreme cool year of 1985. (b) DD8, 29 at Red Cloud, NE in the extreme warm year of 2000 .
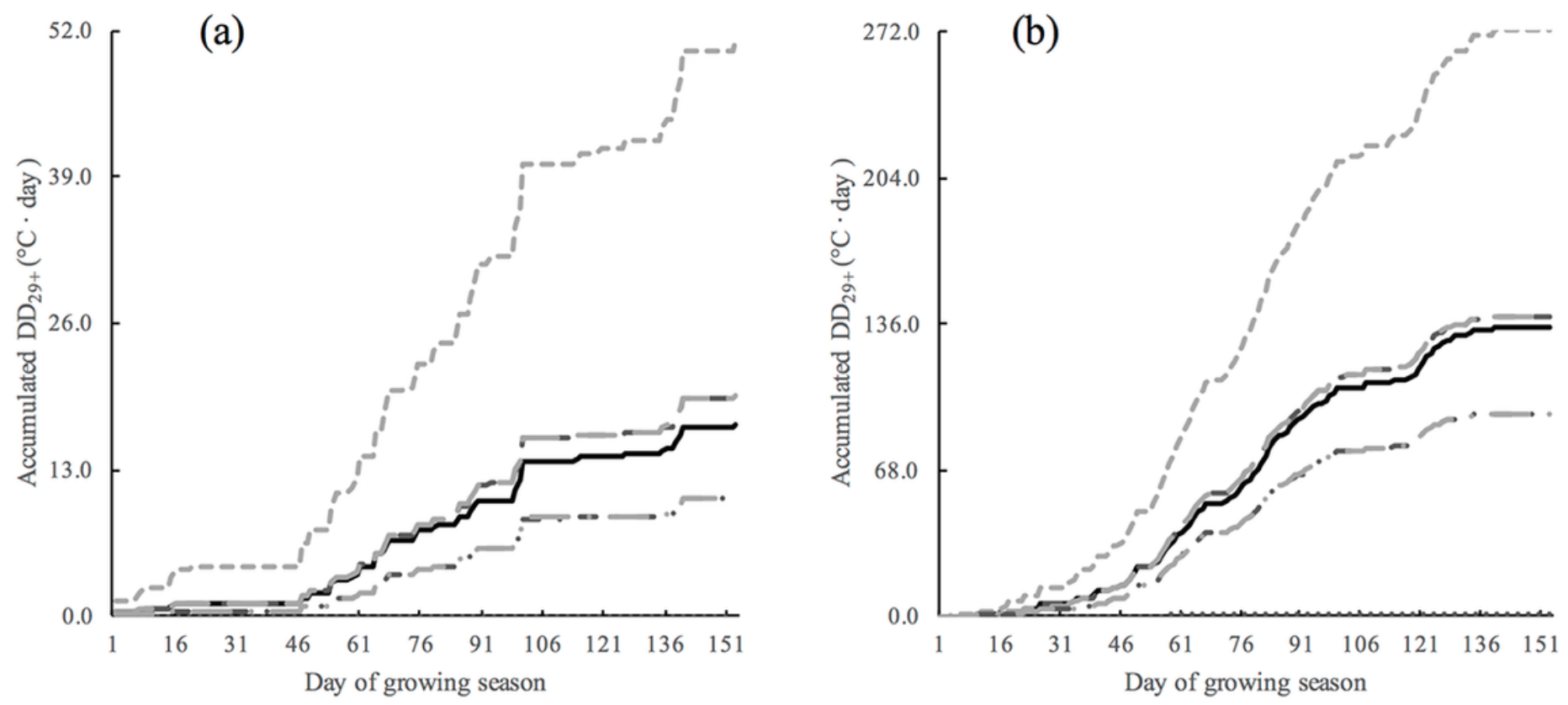
Figure 10

Accumulated degree-days within the growing season of extreme years at particular locations. (a) DD29+ at McCook, NE in the extreme cool year of 1992. (b) DD29+ at Champion, NE in the extreme warm year of 2012. 